\title{
Measuring for sustainability
}

\author{
Pushpam Kumar, Chief Environmental Economist at the United Nations Environment Programme (UNEP), talks to \\ Nature Sustainability about the need to focus on wealth to achieve sustainability.
}

\begin{abstract}
Many say that, given the impacts of COVID-19, there is now a window of opportunity to change how we look at the future. What do you think?

PK: COVID-19 has caused two crises, a health one and an economic one. Both are unprecedented and are going to hurt humanity very deeply. It might take a very long time to recover. Whether the pandemic represents an opportunity or not, and whether or not decision-makers can deliver change will depend on the extent to which society understands what drove the crises and that nature should be part of the recovery plan. COVID-19, like other syndromes before, erupted most likely because of the dysfunctional relationship between humans and nature as exposed by illegal wildlife trade. The costs of such a dysfunctional relationship suggest that it will prove beneficial to protect natural habitats and conserve biodiversity. If in doing so we are confronted with difficult choices, we need to look at the science. If scientific uncertainty is high, we should be conservative and shield nature.
\end{abstract}

\section{How is the UNEP contributing to the current debate about re-building the economy?}

PK: The UNEP, which is the Environmental Secretariat of the UN, makes it a top priority. Several programmes on the human health co-benefits of biodiversity and climate change management are being revised. Through deliberation and engagement with government and civil society, we are achieving consensus that the economy needs reorienting through the lens of inclusive green economy, nature-based solutions, renewable energy and circular economy. The Agenda 2030 has highlighted how the prosperity of the people and the planet are interlinked. The forthcoming UN Environmental Assembly in early 2021 will likely discuss issues like nature-driven jobs, the nature-health nexus and other dimensions. And this is not a comprehensive list of all UNEP efforts to bring nature closer to the economy.

The beyond-GDP discourse is re-gaining momentum. What are the challenges?

PK: The need to move beyond gross domestic product (GDP) has been enduring, from Agenda 21 in 1992, to the Millennium

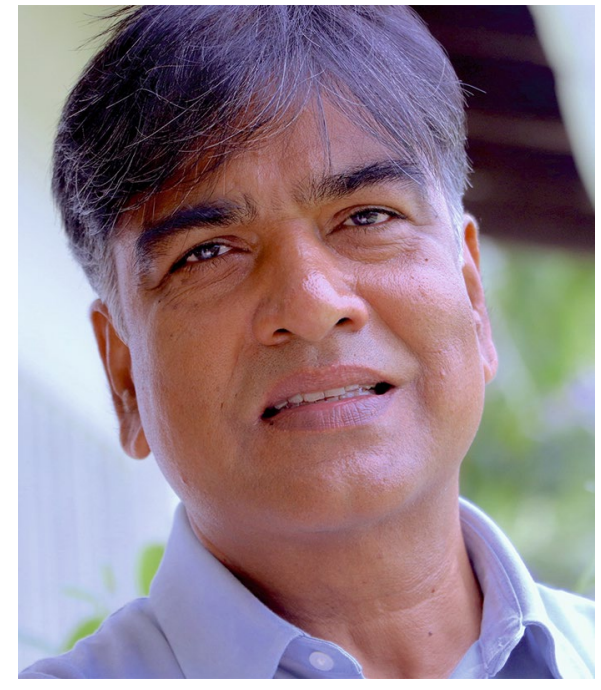

Pushpam Kumar.

Development Goals and later the Sustainable Development Goals (SDGs), although economic scholarship goes much further back. I must make it clear, GDP has its role and relevance. But in order to measure sustainability and well-being, we need to move beyond it. When economists laid the foundation of GDP, they never intended it as an indicator for sustainability. GDP measures the flow of goods and services whereas wealth measures stocks (produced, human and natural capital). Since the well-being of current and future generations depends on how healthy all types of capitals are, the change in per capita wealth over time can better say whether society will be on a sustainable path or not. Too much reliance on GDP is partly due to its early imprint on policy that lasted by inertia and partly due to the absence of structured alternatives and reliable data. However, there is now stronger scholarly consensus about how to measure sustainability and better data availability than in the past. Besides, governments are now open to consider new indicators, and the impacts of COVID-19 will likely help us to move faster.

\section{Can we really measure wealth} effectively across all countries?

PK: Yes, we can. For example, at the UNEP we have developed the Inclusive Wealth indicator that provides a holistic assessment of produced, human and natural capital within a country. It has been estimated for 140 countries. It is a multi-purpose indicator also capable of measuring those less tangible and unseen stocks of wealth - such as skill sets, healthcare and environmental assets - that support human well-being and ultimately set the parameters for sustainable development.

Of course, measuring wealth at the country level is challenging in terms of data, scale, unit and other dimensions, but we need to get started. I am aware of similar efforts to the UNEP one under the name of comprehensive wealth, or true wealth, and they all should be welcomed as long as they are based on credible data and robust methodology.

\section{If the pursuit of wealth rather than} simply income is possible, what else do we need for governments to embrace it? PK: We need to better manage the relationship between nature and society, which is not possible without measuring it. Broader indicators like, for example, Inclusive Wealth can help. But measuring wealth cannot be done without a proactive role of governments. Since a large component of the wealth is public goods such as basic health, education and natural assets, the role of government is critical to support data collection, standardization of approaches, develop and build cohorts of interdisciplinary professionals and a community of practitioners.

Is there hope for a better future for all? PK: I am stubbornly optimistic. Historical evidence strongly suggests we should stay positive. Over the last 200 years or so, we've witnessed significant transformative changes from abolishing slavery to establishing women's rights. So why can't we move in the direction of avoiding the recurrence of pandemics, tackling climate change and loss of biodiversity and safeguarding human well-being by having better measures and management tools? We should have a dream and passion, the rest will follow.

\section{Interviewed by Monica Contestabile}

Published online: 29 June 2020

https://doi.org/10.1038/s41893-020-0570-1

\section{Acknowledgements}

The view may not necessarily and/or comprehensively reflect that of the UNEP. 